Article

\title{
Conditioned Medium from Human Mesenchymal Stromal Cells: Towards the Clinical Translation
}

\author{
Georgy Sagaradze ${ }^{1,2, *}$, Olga Grigorieva ${ }^{1}$, Peter Nimiritsky ${ }^{1,2}\left(\mathbb{D}\right.$, Nataliya Basalova ${ }^{1,2}$, \\ Natalia Kalinina ${ }^{2} \mathbb{D}$, Zhanna Akopyan ${ }^{1,2}$ and Anastasia Efimenko ${ }^{1,2} \mathbb{D}$ \\ 1 Institute for Regenerative Medicine, Medical Research and Education Center, Lomonosov Moscow State \\ University, 27-10, Lomonosovsky av., Moscow 119191, Russia; go.grigorievaolga@gmail.com (O.G.); \\ nimiritsky@gmail.com (P.N.); natalia_ba@mail.ru (N.B.); zhanna.fbm@gmail.com (Z.A.); \\ efimenkoan@gmail.com (A.E.) \\ 2 Faculty of Medicine, Lomonosov Moscow State University, 27-1, Lomonosovsky av., Moscow 119192, Russia; \\ n_i_kalinina@mail.ru (N.K.) \\ * Correspondence: georgy.sagaradze@gmail.com; Tel.: +7(495)531-27-77 (ext. 31-59)
}

Received: 20 March 2019; Accepted: 30 March 2019; Published: 3 April 2019

\begin{abstract}
Mesenchymal stem/stromal cells (MSC) remain a promising tool for regenerative medicine as the efficacy of MSC-based cell therapy has been demonstrated for a broad spectrum of indications. Their therapeutic potency is mainly associated with their ability to secrete multiple factors critical for tissue regeneration. Due to comparable effects along with superior safety MSC conditioned medium (MSC-CM) containing a complex of MSC-secreted products is considered a reasonable alternative to cell therapy. However, the lack of standards regulating bioprocessing, use of proper auxiliary materials, and quality control complicates the development of MSC secretome-based therapeutics. In this study, we suggested several approaches addressing these issues. We manufactured 36 MSC-CM samples based on different xeno-free serum-free chemically defined media (DMEM-LG or MSC NutriStem ${ }^{\circledR} \mathrm{XF}$ ) using original protocols and considered total concentrations of regeneration-associated paracrine factors secreted by human adipose-derived MSC at each time-point of conditioning. Using regression analysis, we retrospectively predicted associations between concentrations of several components of MSC-CM and its biological activity to stimulate human dermal fibroblast and endothelial cell migration in vitro as routine examples of potency assays for cell-based products. We also demonstrated that the cell culture medium might affect MSC-CM biological activity to varying degrees depending on the potency assay type. Furthermore, we showed that regression analysis might help to overcome donor variability. The suggested approaches might be successfully applied for other cell types if their secretome was shown to be promising for application in regenerative medicine.
\end{abstract}

Keywords: regenerative medicine; mesenchymal stem/stromal cells; conditioned medium; secretome; growth factors; manufacturing; quality control; regression analysis

\section{Introduction}

The application of mesenchymal stem/stromal cells (MSC) in regenerative medicine has been intensively studied in hundreds of clinical trials as these cells represent a promising source of multipotent adult stem and progenitor cells for cell therapy and tissue engineering [1,2]. However, excessive MSC heterogeneity hampers profound cell characterization [3-7]. Several safety concerns related to MSC transplantation still remain because of the potential risk of immune reactions and cancer development [8]. Furthermore, poor engraftment and insufficient viability of transplanted cells restrict their therapeutic efficacy [9-12]. 
Therapeutic effects of MSC are generally mediated by various secreted cytokines, growth factors, extracellular matrix proteins and factors involved in matrix remodeling as well as different types of extracellular vesicles [13-17]. MSC-CM that contains cell-secreted products has demonstrated therapeutic benefit for the treatment of ischemic diseases such as myocardial infarction, stroke and acute and chronic hindlimb ischemia, neurodegenerative diseases, spinal cord injury, alopecia, acute and chronic wounds, acute liver injury/failure, lung injury, periodontal tissues injury, male infertility, soft tissue and bone defects [18-23]. There are several clinical trials including the use of MSC-CM for hair follicle regeneration [24], fractional carbon dioxide resurfacing wound healing [25] as well as for inflammatory arthritis [26], and multiple sclerosis [27]. MSC-secreted extracellular vesicles that carry regulatory noncoding RNAs were also used as therapeutic agents to stimulate tissue regeneration [28-32]. Thus, MSC secretome is suggested as a novel cell-free medicinal product that can recapitulate the beneficial effects of MSC and has various advantages in overcoming the limitations and risks associated with cell-based therapy $[33,34]$.

However, significant variability of approaches to MSC-CM bioprocessing has a serious impact on experimental outcomes $[34,35]$. Particularly, the need for disease-specific identity and potency testing due to undefined mechanisms of action of MSC secretome makes development of this class of biopharmaceuticals more complicated, expensive and precarious [1,34,36]. Additionally, the composition of MSC-CM is significantly influenced by donor variability and tissue of MSC origin $[37,38]$ and it should be considered during MSC-CM bioprocessing. In this study, we analyzed how several manufacturing features such as duration of cell conditioning or selection of particular growth medium might influence the composition of human adipose-derived MSC-CM as well as its biological activity in several potency assays routinely used for the development of cell-based therapy products. We then performed regression analysis to estimate power to predict biological activity of MSC-CM samples despite high donor variability and complex composition of MSC-CM.

\section{Results}

\subsection{Characterization of Mesenchymal STEM/Stromal Cells}

Culturing of cells harvested from subcutaneous adipose tissue in the medium supporting the growth of undifferentiated MSC allowed us to get a population of fibroblast-like cells with characteristics of MSC according to criteria from the International Society for Cellular Therapy Statement at the 2nd to 3rd passages [39-41]. MSC expressed CD73, CD90, CD 105, and did not express CD14, CD20, CD34, and CD45 (Figure S1). The isolated cells demonstrated bone mineralization and neutral lipid accumulation in the appropriate culture medium and conditions, thus confirming the ability to differentiate into osteogenic and adipogenic lineages (Figure S2).

\subsection{Development of MSC-CM Bioprocessing Protocol}

Two growth media were selected for producing MSC-CM. First, chemically defined low glucose DMEM (DMEM-LG) was chosen as a conventionally used medium for MSC culture. Second, among commercially available media designed to specifically support growth of undifferentiated MSC we selected a defined, xeno-free, serum-free MSC NutriStem medium (Biological Industries, Israel). It is important to note that only basal media without nutrimental supplements (FBS or NutriStem supplement) were used for MSC conditioning.

To develop the original MSC-CM bioprocessing protocol, we firstly assessed cell viability dynamics during long-term conditioning. Both media supported appropriate viability of MSC during long-term conditioning in supplement-free conditions (all cultures contained $\geq 70 \%$ of viable cells at least for 12 days) (Table 1). The level of cell proliferation in these culture conditions was relatively low due to the lack of supplements and did not differ between the media. 
Table 1. Viability of mesenchymal stem/stromal cells during long-term conditioning in two basal media. The data from three independent experiments have been presented as means \pm SD.

\begin{tabular}{ccccccc}
\hline $\begin{array}{c}\text { Time, Days/ } \\
\text { Growth Medium }\end{array}$ & 3 Days & 5 Days & 7 Days & 10 Days & 12 Days & 14 Days \\
\hline DMEM & $80.3 \pm 1.5$ & $77.0 \pm 2.6$ & $78.3 \pm 3.2$ & $71.7 \pm 3.8$ & $90.7 \pm 6.7$ & $59.7 \pm 11.7$ \\
\hline Nutri Stem & $76.0 \pm 4.0$ & $77.3 \pm 5.0$ & $73.3 \pm 11.2$ & $72.0 \pm 8.5$ & $73.7 \pm 13.1$ & $76.0 \pm 5.2$ \\
\hline
\end{tabular}

To determine the appropriate period of MSC conditioning, we analyzed total concentrations of selected growth factors in MSC-CM on certain days. According to the literature data and our previous results [42-44], we chose four key growth factors, which were shown to substantially contribute to positive effects of MSC on reparative and regenerative processes in damaged tissues, namely vascular endothelial growth factor (VEGF), hepatocyte growth factor (HGF), fibroblast growth factor 2 (FGF2), and angiopoetin-1 (Angpt-1). Peak factor concentrations were mostly reached at days 7 or 10 in both media (Figure 1). Due to minor differences between the concentrations of growth factors at days 7 and 10 and the substantial reduction of MSC-CM manufacturing duration, the 7-day protocol of MSC conditioning was selected for further experiments.
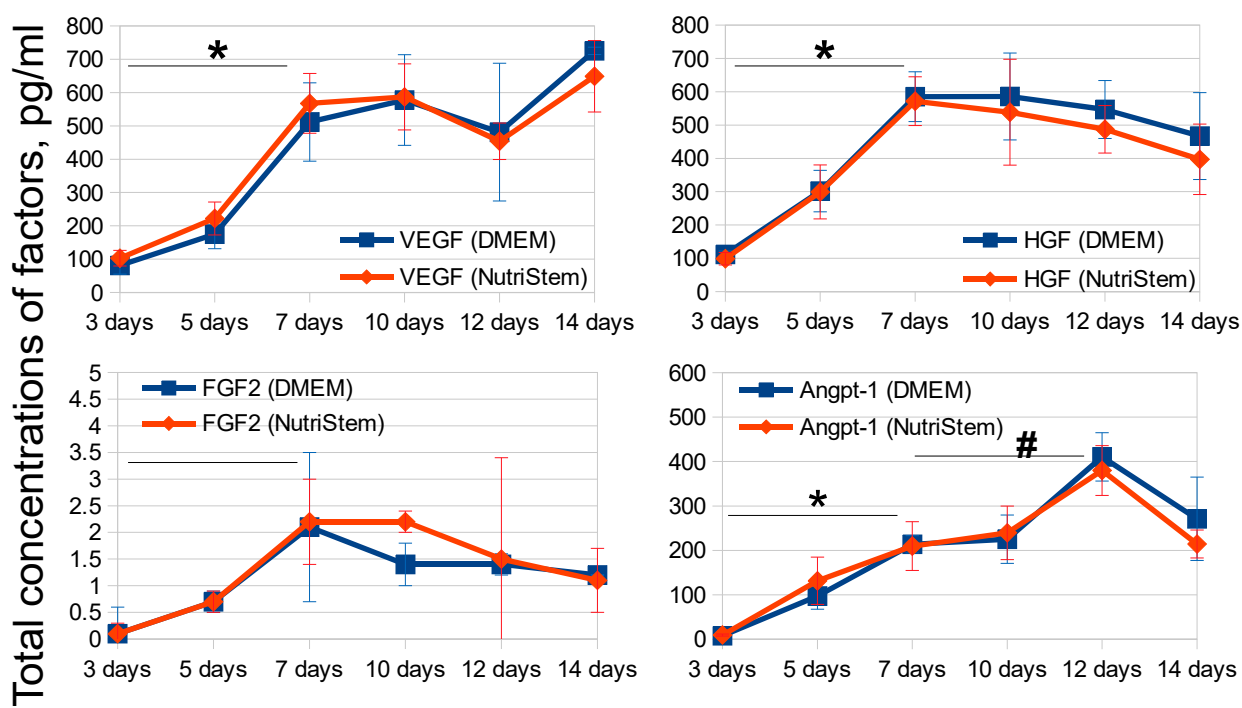

Figure 1. Total growth factor concentrations in DMEM- (blue lines) and NutriStem-based (red lines) MSC-CM samples $(n=3)$ collected independently at each timepoint of MSC conditioning. The data are presented as mean concentrations in $\mathrm{pg} / \mathrm{mL} \pm \mathrm{SD}$. MSC-CM samples were analyzed in three independent replicates for both media. Only MSC-CM samples based on the same medium were compared. ${ }^{*} p<0.05$ compared to the factor concentration at day $3, \# p<0.05$ compared to the factor concentration at day 7 .

To establish whether MSC growth medium may have influenced the composition of MSC-CM, we compared factor concentrations in MSC-CM samples $(n=36)$ manufactured using DMEM-LG or NutriStem. Pigment-epithelial derived factor (PEDF) was also included in the analysis as overrepresented MSC-CM protein possibly counterbalancing its angiogenic effects. The concentration of VEGF and PEDF were higher in DMEM-LG conditioned medium while HGF and Angpt-1 concentrations were higher in NutriStem MSC-CM samples (Figure 2). Thus, a possible impact of the cell culture medium on MSC-CM composition was considered in further experiments. It is worth noting that the means of growth factor concentrations in the 36 analyzed samples differed from the values presented in Figure 1, which obviously indicates the reason for analyzing large sample groups. 


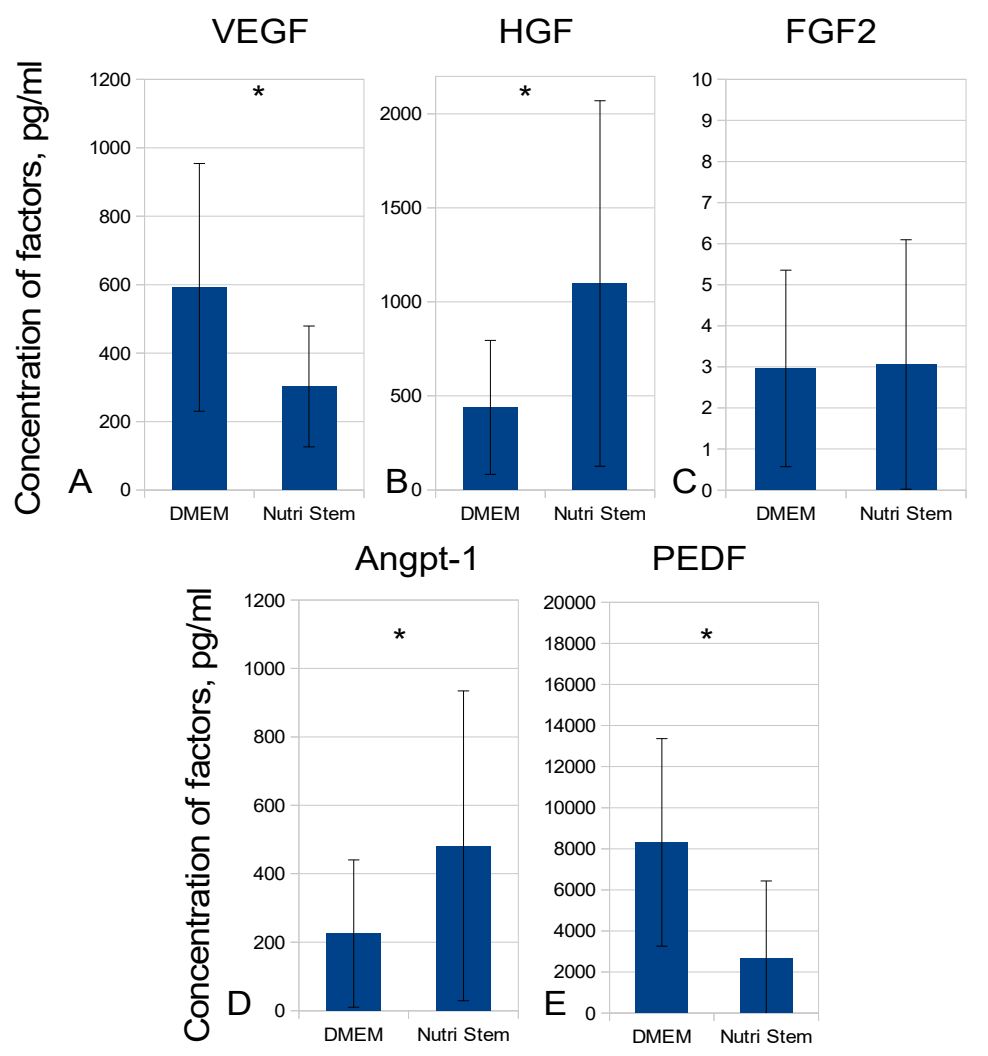

Figure 2. Comparison of growth factor concentrations in MSC-CM based on different MSC culture media at day 7. The data are presented as mean concentrations in $\mathrm{pg} / \mathrm{mL} \pm \mathrm{SD}$. ${ }^{*} p<0.05$ after Student's $t$-test analysis. All manufactured 36 MSC-CM samples were analyzed.

\subsection{Evaluation of MSC-CM Functional Activity in Vitro}

To assess functional activity of MSC-CM samples, we used two well-established in vitro models reflecting important processes for tissue repair. Firstly, non-directional migration of human dermal fibroblasts stimulated by MSC secreted products were analyzed in the scratch assay. Secondly, directional migration of human endothelial cells stimulated by MSC-CM was measured using the automated xCELLigence system to allow real-time registration of the process. Both the studied MSC-CM types stimulated human dermal fibroblast migration as well as human endothelial cell migration, however, the effects of NutriStem MSC-CM samples were less expressed (Figures 3 and 4). 


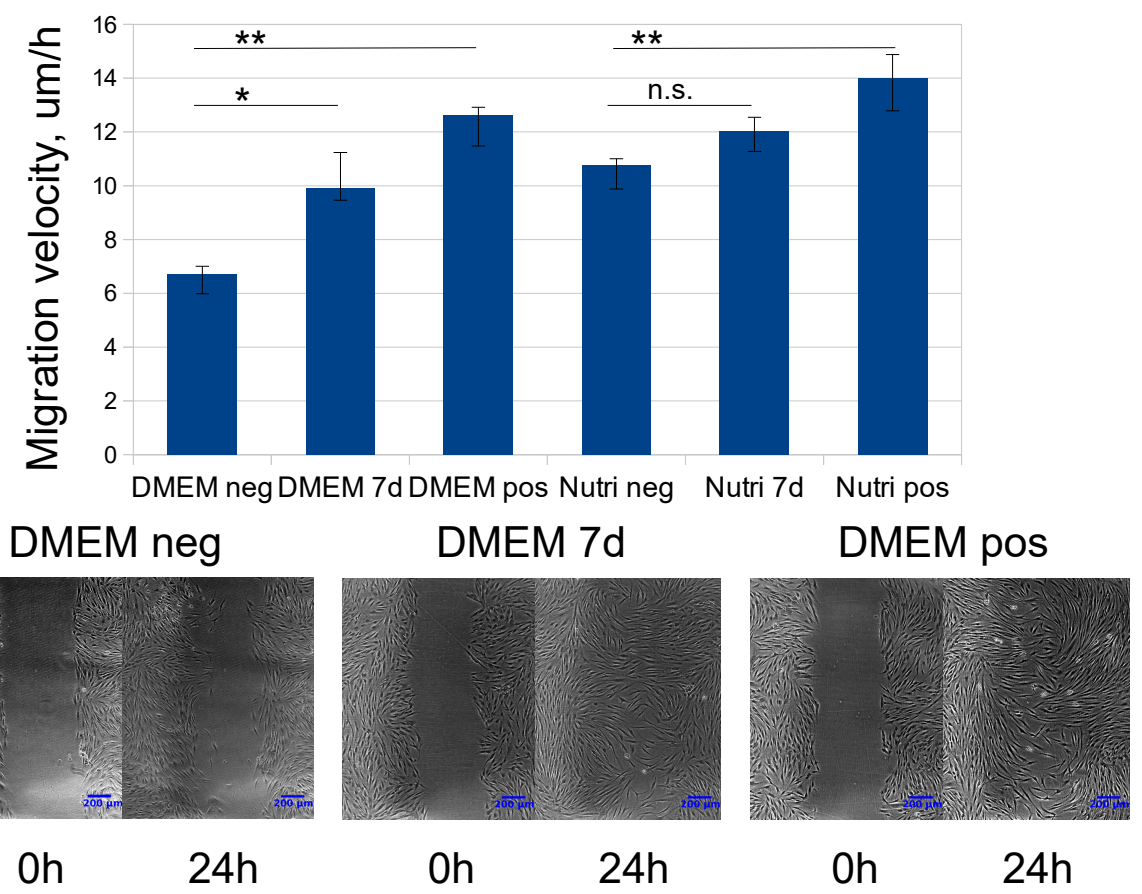

Figure 3. Human dermal fibroblast migration (scratch wound assay) stimulated by MSC-CM obtained after 7 days of long conditioning in DMEM-LG or NutriStem. Graph: DMEM neg-basal medium DMEM-LG $(n=5)$, DMEM pos-DMEM-LG + 10\% FBS $(n=5)$, Nutri neg-basal NutriStem medium $(n=5)$, Nutri pos-NutriStem $+10 \%$ NutriStem Supplement $(n=5)$, DMEM $7 \mathrm{~d}(n=12)$ and Nutri $7 \mathrm{~d}$ $(n=15)$-MSC-CM samples obtained after conditioning of MSC for 7 days. After the scratch was made, either samples or controls were added to the cells for $24 \mathrm{~h}$. Data are presented as medians and 25th-, 75th percentiles of human dermal fibroblast migration in um $/ \mathrm{h} .{ }^{*} p<0,05$; ${ }^{* *} p<0.01 ;$ n.s. $-p=0.08$. Low panel: Scratch wound closure at the start point $(0 \mathrm{~h})$ and after $24 \mathrm{~h}$; scalebar marks $200 \mathrm{um}$.

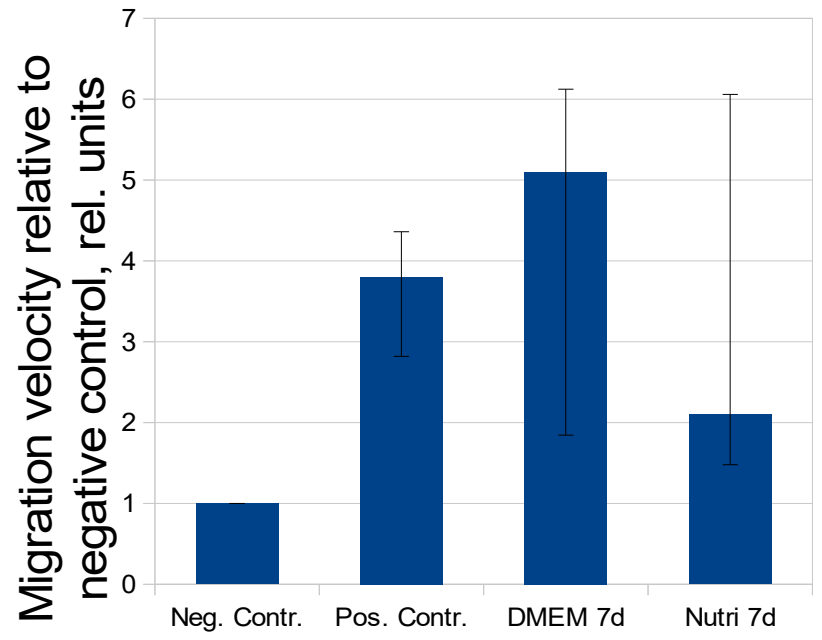

Figure 4. Directional migration of human endothelial cells EA.hy926 over a period of $4 \mathrm{~h}$ toward MSC-CM samples obtained after 7 days of long conditioning. Neg. Contr-basal medium DMEM-LG $(n=3)$, Pos. Contr-DMEM-LG + 10\% FBS $(n=3)$, DMEM 7d $(n=6)$ and Nutri $7 \mathrm{~d}(n=4)-\mathrm{MSC}-\mathrm{CM}$ samples. Basal DMEM-LG was used as a negative control for all the CM samples due to a lower relative potency of NutriStem supplemented medium compared to basal medium (1.59 fold; data are not presented). The relative cell migration velocity is presented. The data is displayed as medians and 25th, 75th percentiles. ${ }^{*} p<0.05$. 


\subsection{Development of the Prediction Model for MSC-CM Potency Using Regression Analysis}

To define the factors associated with the potency of MSC-CM samples in the studied in vitro models, we performed regression analysis. It is important to note that the type of MSC growth medium was also considered as a possible predictor of the potency due to its discrepant influence on factor concentrations. Surprisingly, we showed that Angpt-1 concentration was the most potent predictor of human dermal fibroblast migration stimulated by MSC-CM. MSC growth medium was not considered a reliable predictor $(p=0.448)$. Using only Angpt- 1 concentrations we divided MSC-CM sample into groups with differing potency $(p<0.086)$ (Table 2, Figure 5).

Table 2. Prediction model for MSC-CM sample potency to stimulate human dermal fibroblast migration; $n=24$ for train group, $n=12$ for validation group.

\begin{tabular}{|c|c|c|c|}
\hline Predictor. & Coefficient & $P$-Value & $95 \%$ Conf. Interval \\
\hline Intercept & 0.58 & 0.53 & $-1.9 ; 1.25$ \\
\hline VEGF & 0.67 & 0.46 & $-1.35 ; 0.99$ \\
\hline HGF & 0.80 & 0.27 & $-0.82 ; 1.62$ \\
\hline FGF2 & 0.67 & 0.44 & $-0.74 ; 2.53$ \\
\hline Angpt-1 & -1.83 & 0.08 & $-3.81 ; 0.78$ \\
\hline PEDF & 1.14 & 0.15 & $-0.48 ; 1.64$ \\
\hline Medium type & -1.17 & 0.45 & $-2.69 ; 2.62$ \\
\hline \multicolumn{4}{|c|}{ Single factor analysis } \\
\hline Predictor & Coefficient & P-value & $95 \%$ Conf. Interval \\
\hline Intercept & 0.09 & 0.85 & $-0.85 ; 1.03$ \\
\hline Angpt1 & -1.16 & 0.11 & $-2.59 ; 0.27$ \\
\hline
\end{tabular}

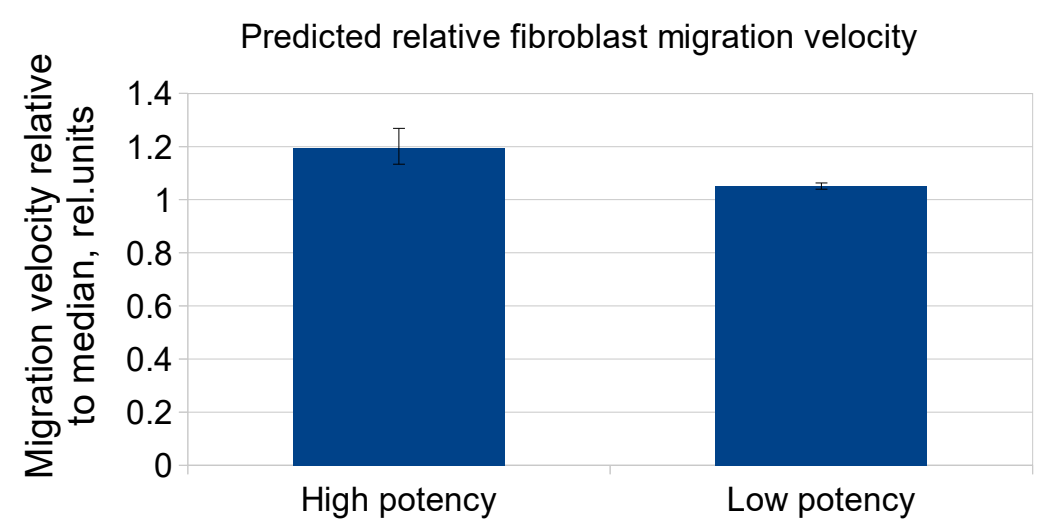

Figure 5. Comparison of two groups of MSC-CM samples that differed in potency. The data are presented as medians, 25th, and 75th percentiles, $p<0.086$ between these groups, $n=10$ for High potency group, $n=2$ for Low potency group.

It was found that neither analyzed factors were untrustworthy to predict the potency of MSC-CM to stimulate endothelial cell migration (Table 3). Therefore, considering possible associations of more than one factor with MSC-CM effects and the ambiguous influence of the cell growth medium on their concentrations, we performed regression analysis for DMEM-LG and NutriStem-based MSC-CM samples separately. 
Table 3. Prediction model for MSC-CM sample potency to stimulate human endothelial cell migration; $n=20$ for train group, $n=11$ for validation group.

\begin{tabular}{cccc}
\hline Predictor & Coefficient & P-Value & 95\% Conf. Interval \\
\hline Intercept & 2.75 & 0.61 & $-7.7 ; 13.2$ \\
\hline VEGF & 2.76 & 0.31 & $-2.52 ; 8.04$ \\
\hline HGF & 0.66 & 0.72 & $-2.96 ; 4.29$ \\
\hline FGF2 & 8.78 & 0.69 & $-34.11 ; 51.67$ \\
\hline Angpt1 & -1.46 & 0.70 & $-9.01 ; 6.09$ \\
\hline PEDF & 0.89 & 0.54 & $-1.99 ; 3.77$ \\
\hline Medium type & -4.10 & 0.70 & $-24.8 ; 16.58$ \\
\hline
\end{tabular}

It was demonstrated that FGF2 concentration analysis was sufficient to classify DMEM-LG MSC-CM samples on the basis of their potency to stimulate the migration of human endothelial cells (Table 4, Figure 6A). However, the potency predictors of NutriStem MSC-CM were not discovered (Table 5, Figure 6B).

Table 4. Prediction model for DMEM-LG MSC-CM sample potency to stimulate human endothelial cell migration; $n=8$ for train group, $n=5$ for validation group.

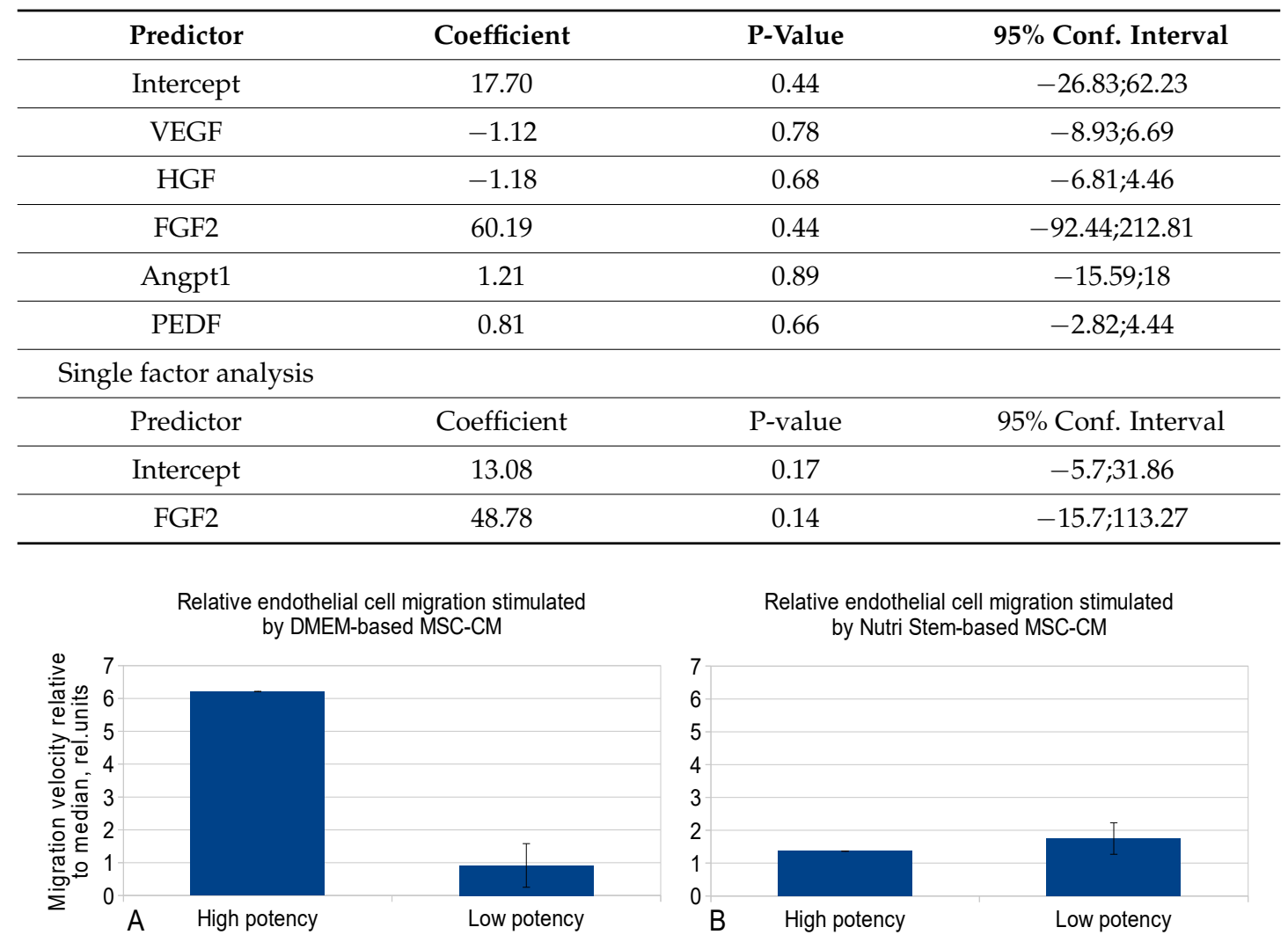

Figure 6. Comparison of two groups of MSC-CM samples that differed in potency to stimulate human endothelial cell migration. A-Samples manufactured using DMEM-LG, $n=1$ for High potency group, $n=4$ for Low potency group; B-NutriStem, $n=1$ for High potency group, $n=4$ for Low potency group. The data are presented as means \pm SD. 
Table 5. Prediction model for NutriStem MSC-CM sample potency to stimulate human endothelial cell migration; $n=7$ for train group, $n=5$ for validation group.

\begin{tabular}{cccc}
\hline Predictor & Coefficient & P-Value & 95\% Conf. Interval \\
\hline Intercept & -1.04 & 0.95 & $-30.57 ; 28.49$ \\
\hline VEGF & 4.81 & 0.76 & $-25.56 ; 35.17$ \\
\hline HGF & -0.72 & 0.96 & $-28.07 ; 26.63$ \\
\hline FGF2 & -1.73 & 0.91 & $-32.6 ; 29.13$ \\
\hline Angpt1 & 2.54 & 0.81 & $-18.66 ; 23.8$ \\
\hline PEDF & 0.45 & 0.98 & $-37.8 ; 38.7$ \\
\hline Single factor analysis & & & $95 \%$ Conf. Interval \\
\hline Predictor & Coefficient & P-value & $-10.79 ; 10.67$ \\
\hline Intercept & -0.06 & 0.99 & $-10.84 ; 26.2$ \\
\hline VEGF & 7.68 & 0.42 &
\end{tabular}

Taken together, the use of regression analysis might allow for the prediction of the potency of MSC-CM samples using only concentrations of a restricted number of secreted factors. This could simplify MSC-CM quality control as well as the donor selection procedure.

However, during analysis one should take into account possible interactions between distinct growth factors. In this study, several interactions were considered based on discovered significant rank correlations between HGF release and FGF2, VEGF, PEDF concentrations. Nevertheless, their inclusion in the model did not change the results of the analysis seriously.

\section{Discussion}

According to the current concepts, MSC could orchestrate tissue development, maintenance and repair, mostly by producing multiple secretory factors [45-51]. Therefore, the application of MSC-CM might be an effective strategy for regenerative medicine. To date, several MSC-derived conditioned media were tested on various diseases and many of them showed positive results [22]. An additional benefit is that MSC-CM might be an off-the-shelf material that could be used to treat patients promptly without MSC isolation and subsequent culture. However, despite the clear benefits of using MSC-CM for regenerative medicine, several issues must be addressed before its successful clinical application. Among them, one of the most important is a lack of common recommendations or standards for bioprocessing and quality control of MSC secretome-based therapeutics [52]. In this study, we suggested universal approaches that might help to overcome these issues and, finally, optimize the development of MSC-CM based products in general.

To develop the MSC-CM bioprocessing protocol we selected two growth media for MSC conditioning: DMEM due to its wide application in the manufacturing of MSC-based cell products, including the clinical trials [53] and NutriStem as one of the specific media with great potential to support growth and functional properties of undifferentiated human MSC. Both media were chemically defined, available as GMP-grade media and appropriate for cell manufacturing. It is critical to note that we used only basic media for MSC conditioning without adding the specific nutrimental supplements, because of their high risk influence on the biosafety of a final product and serious challenges for further clinical translation [54]. We showed that both media supported appropriate viability of MSC during the long-term conditioning in supplement-free conditions.

Due to complex composition of MSC-CM, it was necessary to focus on components that would reflect its regenerative potency for a specific condition. In our study, we selected several factors crucial for MSC secretome-mediated tissue regeneration, which was also confirmed by our previous data [42-44]. VEGF, an important pro-angiogenic and neurotrophic factor [43], is produced by MSC and served as one of the main mediators in MSC interaction with endothelial cells. Particularly, 
VEGF expression by MSC was associated with the stimulation of angiogenesis and endothelial cell proliferation in both small and large animal studies [55], and blocking of VEGF in MSC-CM resulted in significant reduction in its ability to stimulate angiogenesis [42,44]. On the contrary, PEDF, another factor highly represented in MSC secretome [56], has anti-angiogenic effects; the ratio of VEGF/PEDF produced by MSC may indicate the ability of the cells to stimulate angiogenesis [57]. MSC also secretes HGF, a factor with angiogenic, anti-apoptotic and immune modulating activity shown to be critical in several in vitro and in vivo therapeutic effects of MSC $[43,58]$. FGF2, a strong mitogenic and pro-migratory factor for fibroblasts, has the potential to promote angiogenesis and to increase survival and proliferation of stem cells in vivo [59,60].

Obviously, the panel of factors evaluated in MSC-CM may vary depending on potential therapeutic mechanisms for a specific disease. Particularly, in several injury models, either a complex of growth factors from MSC-CM as well as other bioactive components of MSC secretome (i.e., extracellular vesicles) might confer the principal potency for restoration [61]. The components of MSC-CM also might differ by their accumulation dynamics in cell growth medium, so we considered the peak concentrations of several factors to improve the performance of the bioprocessing protocol. Importantly, it was demonstrated that the type of a cell growth medium affected secretory potential of MSC, which was in accordance with literature data [62,63].

To optimize specific biological activity testing of MSC-CM, we suggested to perform regression analysis. Based on initial results of the testing on biological models, this approach can help to select MSC-CM factors, which concentrations are closely associated with the specific biological activity of MSC-CM. This might make possible to predict specific activity using precise instrumental analysis, thus bypassing expensive and laborious biological assays. Accordingly, the estimation of the concentrations of irrelevant MSC-CM factors might be omitted.

In this study, we demonstrated that FGF2 concentration in MSC-CM was associated with DMEM-based CM-stimulated endothelial cell migration velocity. Importantly, these results were concordant with the mechanisms of action of this factor [60]. However, the similar results were not obtained for NutriStem-based MSC-CM samples possibly due to direct substantial influence of the basal medium on the potency. Unexpectedly, it was also demonstrated that Angpt- 1 concentration in MSC-CM was inversely associated with CM-stimulated fibroblast migration velocity independently of the type of cell culture medium. Indeed, it did not fit with the well-established superior pro-migratory potential of FGF2 [59]. Nevertheless, these results might be interpreted as evidence that Angpt-1 concentrations predicted activity to stimulate fibroblast migration for the set composed of DMEM and NutriStem MSC-CM samples, even despite lack of established biological associations. Use of such an approach allows to make MSC-CM bioprocessing protocols more flexible in relation to the choice of raw materials.

Noteworthy, regression analysis used in this study has several limitations. It is impossible to consider all the interactions of soluble factors in MSC-CM. Furthermore, the analyzed components of MSC-CM could have synergistic or antagonist effects on each other which might distort their real impact on biological activity of MSC-CM, but couldn't be revealed by mathematical modeling. Nevertheless, use of the regression analysis might be rational. We interpreted the release of factors as endpoints that might vary due to donor-associated heterogeneity or influence of other MSC-CM components. The obtained results would reflect associations of factor concentrations with specific biological activity of a sample considering its variability but possibly irrelevant to its biological function.

Taken together, our results have demonstrated the applicability of the approaches to MSC-CM bioprocessing and quality control optimization. Despite hurdles associated with the development of MSC secretome-based products, we tried to circumvent the high variability between donors and indicate a practical way to the choice of relevant quality control criteria. We suggest that these approaches might be adapted for other cell types and their secretomes promising for application in regenerative medicine. 


\section{Materials and Methods}

\subsection{Patients}

Thirty patients were included in the study. They underwent surgery because of general surgical pathology, kidney and bladder revision. Exclusion criteria included any patient aged less than 18 years and more than 70 years, autoimmune pathologies, cancer (even in the past history), acute or chronic inflammatory disease, type 2 diabetes mellitus, acute myocardial infarction in the previous six months, long-term hormone or antibiotics therapy, hematological disorders, stroke or craniocerebral injury in the previous 12 months, polyvalent allergy and pregnancy. The clinical features of the patient cohort are presented in Table S1. All procedures performed with tissue samples from patients were in accordance with the Declaration of Helsinki and approved by the Ethics Committee of Lomonosov Moscow State University (IRB00010587), protocol \#4 (2018). Each donor participated in the study, signed an informed written consent form for harvesting and using adipose tissue samples as well as for handling clinical data for research purposes.

\subsection{Isolation of Adipose-Derived MSC}

Subcutaneous adipose tissue samples $(0.5-5 \mathrm{~mL})$ harvested during surgery were homogenized and digested in collagenase I (200 U/mL, Worthington Biochemical) and dispase (40 U/mL, Sigma, St. Louis, MO, USA) solutions under agitation for 30-40 $\mathrm{min}$ at $37^{\circ} \mathrm{C}$. Then tissue was centrifuged at $200 \mathrm{~g}$ for $10 \mathrm{~min}$; supernatant was discarded. Erythrocytes were removed from the MSC pellet by a brief hypoosmotic shock. Then, cell suspension was filtered through a sieve (BD Falcon Cell Strainer, $100 \mathrm{um}$, Franklin Lakes, NJ, USA) and centrifuged at $200 \mathrm{~g}$ for $10 \mathrm{~min}$. The final pellet was resuspended in culture medium. The cells were cultured in standard conditions $\left(5 \% \mathrm{CO}^{2} ; 37{ }^{\circ} \mathrm{C}\right)$ in Advance Stem Cell Basal Medium (ASCBM, HyClone, Marlborough, MA, USA) with 10\% of Advance Stem Cell Growth Supplement (HyClone), and $100 \mathrm{U} / \mathrm{mL}$ penicillin/streptomycin (HyClone). Unattached cells were washed off $24 \mathrm{~h}$ after isolation, and then, medium was changed every 3 to 4 days. The yield of cells was $4-7 \times 10^{4}$ of attached cells per $\mathrm{ml}$ of tissue. Cells were passaged at $70 \%$ confluency using HyQTase solution (HyClone).

\subsection{Collection of MSC conditioned medium}

MSC at 4-5th passages were seeded with a density of $3 \times 10^{3}$ cells $/ \mathrm{cm}^{2}$ on uncoated culture plastic (Corning) and were cultured to $70-80 \%$ confluence in $100 \mathrm{~mm}$ culture dishes. Then MSC were washed thoroughly 3 times using $10 \mathrm{~mL}$ of $\mathrm{HBSS}$ without $\mathrm{Ca}_{2}{ }^{+}$and $\mathrm{Mg}^{+}$, and replenished with MSC NutriStem XF Basal Medium (Nutristem, Biological Industries, Beit-Haemek, Israel) or DMEM with low glucose (DMEM-LG, HyClone). Cells were cultured in standard conditions $\left(5 \% \mathrm{CO}_{2} ; 37^{\circ} \mathrm{C}\right)$ for different time periods. Then, conditioned media samples were collected, centrifuged at $3000 \mathrm{rpm}$ for $10 \mathrm{~min}$ at $4{ }^{\circ} \mathrm{C}$ to remove cell debris, then frozen in aliquots at $-70^{\circ} \mathrm{C}$. $36 \mathrm{MSC}-\mathrm{CM}$ samples were manufactured ( $n=21$ for DMEM-LG, $n=15$ for NutriStem).

\subsection{Analysis of Cell Viability}

The quantity and viability of MSC were assessed at the end of the experiment by staining with trypan blue solution. Cell viability was interpreted as the ability of viable cells to eject the trypan blue stain. The amount of viable (bright) and dead (blue) cells was evaluated using the automated cell counter Countess (Invitrogen, Carlsbad, CA, USA). Cell viability was determined as a ratio of viable cells to the total cell amount. To estimate cell viability during long-term conditioning, the cells were grown in separate dishes and were analyzed in certain time points independently. 


\subsection{MSCs Immunophenotyping and Differentiation Assays}

To confirm that MSC were multipotent mesenchymal stromal cells we analyzed their immunophenotype according to the published criteria [39]. Cells were stained with anti- CD73, CD90, CD105, CD14, CD20, CD34, CD45 antibodies and appropriate isotype control antibodies (MSC Phenotyping Kit, Miltenyi Biotec, Bergisch Gladbach, Germany) and analyzed using flow cytometry.

The potential of MSC for osteogenic and adipogenic differentiation was tested using standard techniques in vitro. Briefly, osteogenic differentiation was induced by plating $6 \times 10^{4}$ MSC on a 24-well plate and incubated in an Advance Stem Cell Osteogenic Medium (HyClone) containing 10\% Advance Stem Cell Supplement and $100 \mathrm{U} / \mathrm{mL}$ penicillin/streptomycin for 21 days. Differentiation efficiency was analyzed using Alizarin Red S staining for calcium accumulation. Adipogenic differentiation was induced by the incubation of MSC in Advance Stem Cell Adipogenic Medium (HyClone) containing 10\% Advance Stem Cell Supplement and $100 \mathrm{U} / \mathrm{mL}$ penicillin/streptomycin for 18 days. Cells accumulated intracellular lipids were analyzed using Oil-Red-O staining.

\subsection{Analysis of Concentrations of Growth Factors in MSC-Conditioned Medium by ELISA}

The concentrations of VEGF, HGF, FGF2, Angpt-1 and PEDF in MSC-CM samples were analyzed using ELISA (R\&D Systems) according to the manufacturer's instructions. Factor concentrations were determined in conditioned medium collected from independent cell culture plates. The cells isolated were seeded on cell culture dishes. Then, the medium was collected, centrifuged and frozen. The total release of factors was calculated based on the analysis of secretome samples at every time point.

\subsection{Migration of Fibroblasts in the Scratch Assay}

Scratch assay is a specific test with an artificial wound scrapped mechanically in a confluent cell monolayer. Fibroblasts activated by an empty plastic area move from the edge to the center of the wound up to wound closure. Several factors like FBS or other factors, contained in MSC-CM, might have an influence on cell motility. Human skin fibroblasts were grown to confluent in 24-well plates in DMEM-LG containing 10\% of the FBS. Then, fibroblasts were deprived in DMEM with $0 \%$ FBS for $24 \mathrm{~h}$. Cell monolayers were scratched with a $1 \mathrm{~mL}$ pipette tip and briefly rinsed. Then, the sample of MSC-CM or DMEM-LG supplemented with 10\% FBS as a positive control or serum-free DMEM-LG as a negative control were added. Following this, culture plates were transferred onto the microscopic stage of a motorized Nikon Ti inverted microscope (Nikon, Japan) equipped with the 5x objective, on-stage culture box, temperature controller set to $37^{\circ} \mathrm{C}$ and continuous carbogen administration unit. The time-lapse series was continuously acquired every $15 \mathrm{~min}$ over $24 \mathrm{~h}$ using a cooled CCD camera (Nikon, Tokyo, Japan) and the "Mark and Find" application in NIS Elements (Nikon, Japan) to achieve simultaneous image acquisition in all 24 wells of the plate. This frequency ensured that in each series two successive displacements of a cell were resolved and all cell divisions were captured to be excluded from the analysis later on. The time series were analyzed by manual tracking of all cells on the edge of the experimental wounds and their velocity was measured in two randomly chosen positions of the wounded areas using free ImageJ software, Madison, WI, USA. Routinely, 50 cells were tracked for each data point.

\subsection{Endothelial Cell Migration Analysis in the xCELLigence RTCA DP System}

To analyze endothelial cell migration using the CIM-Plate 16, human endothelial cells EA.hy926 were cultured in DMEM with high glucose supplemented with $10 \%$ FBS; cells were deprived in serum-free DMEM for 6 to $8 \mathrm{~h}$ prior to the experiment and seeded $30 \times 10^{4}$ cells in $50 \mathrm{uL}$ of serum-free DMEM per well into the upper chambers of the CIM-Plate 16. Samples of MSC-CM (160 uL per well) were placed into the lower chambers. DMEM supplemented with $10 \%$ FBS was used as a positive control and serum-free DMEM served as a negative control. Then CIM-Plate 16 was placed in the RTCA DP Instrument (Roche, Basel, Switzerland) equilibrated in a $\mathrm{CO}_{2}$ incubator. Endothelial 
cell migration was continuously monitored using the RTCA DP Instrument. MSC-CM provided a strong chemoattractant signal, which induced the directional migration of endothelial cells through the micropores of the CIM-Plate 16. Migrating cells were detected by the electronic sensing microelectrodes, producing changes in the measured Cell Index values. Time-dependent cell migration was monitored over $4 \mathrm{~h}$. All experiments were performed in duplicates. The RTCA Software 1.2 was used to calculate Cell Index values for MSC-CM-mediated endothelial cell migration.

\subsection{Regression Analysis}

The samples were randomized to training and validation groups prior to analysis (2:1 for fibroblast migration and initial endothelial cell migration, 1.5:1 for cell growth medium-specific endothelial cell migration). Growth factor concentrations in MSC-CM samples were standardized prior to regression model building. We used the Python StatsModels library and the Logit model, to perform regression analysis. For fibroblast scratch assay we categorized our data into two groups according to their specific activity: The first group consisted of samples with below median activity $(n=18)$, the second group included samples with equal to or above median activity $(n=18)$. For endothelial cell migration we split our data into two groups similarly: The first group consisted of 20 samples, the second included 11 more potent samples. We selected factor concentrations as well as the type of cell culture medium as independent variables.

\subsection{Statistical Analysis}

Statistical analysis was performed using RStudio. The normality was tested using the Shapiro-Wilk test. Normally distributed data were compared using a Student's t-test; data that were not normally distributed were compared using the Mann-Whitney U-test or the Kruskal-Wallis test. Multiple comparisons were made using the Kruskall-Wallis test with subsequent application of Dunn criteria. Correlations were calculated using the Hmisc R package. Statistical significance was defined as $p$-value $<0.05$.

Supplementary Materials: Supplementary materials can be found at http:/ / www.mdpi.com/1422-0067/20/7/ 1656/s1.

Author Contributions: Conceptualization, G.S., N.K., A.E.; methodology, G.S., O.G., A.E.; data acquisition, O.G., P.N., N.B.; data interpretation, G.S.; resources, N.K., Z.A., A.E.; writing-original draft preparation, G.S., A.E.; writing — review and editing, N.B., N.K.; project administration, A.E.; funding acquisition, G.S., Z.A.

Funding: This study was conducted using biomaterial collected under Lomonosov Moscow State University project "Noah's Ark" (No 14-50-00029) and using equipment purchased as a part of Moscow State University Program of Development. The study was supported by the Russian Foundation for Basic Research (grant No 18-315-00403).

Conflicts of Interest: The authors declare no conflicts of interest.

$\begin{array}{ll}\text { Abbreviations } \\ \text { MSC } & \text { mesenchymal stem/stromal cells } \\ \text { CM } & \text { conditioned medium } \\ \text { DMEMLG } & \text { Dulbecco's Modified Eagle Medium with low glucose content } \\ \text { VEGF } & \text { vascular endothelial growth factor } \\ \text { HGF } & \text { hepatocyte growth factor } \\ \text { FGF2 } & \text { basic fibroblast growth factor } \\ \text { Angpt-1 } & \text { angiopoietin-1 } \\ \text { PEDF } & \text { pigment epithelial cells derived factor } \\ \text { FBS } & \text { fetal bovine serum }\end{array}$




\section{References}

1. Robb, K.P.; Fitzgerald, J.C.; Barry, F.; Viswanathan, S. Mesenchymal stromal cell therapy: Progress in manufacturing and assessments of potency. Cytotherapy 2018, 1-18. [CrossRef] [PubMed]

2. Fitzsimmons, R.E.B.; Mazurek, M.S.; Soos, A.; Simmons, C.A. Mesenchymal Stromal/Stem Cells in Regenerative Medicine and Tissue Engineering. Stem Cells Int. 2018, 2018, 1-16. [CrossRef] [PubMed]

3. Samsonraj, R.M.; Raghunath, M.; Nurcombe, V.; Hui, J.H.; van Wijnen, A.J.; Cool, S.M. Concise Review: Multifaceted Characterization of Human Mesenchymal Stem Cells for Use in Regenerative Medicine. Stem Cells Transl. Med. 2017, 6, 2173-2185. [CrossRef]

4. McLeod, C.M.; Mauck, R.L. On the origin and impact of mesenchymal stem cell heterogeneity: New insights and emerging tools for single cell analysis. Eur. Cells Mater. 2017, 34, 217-231. [CrossRef]

5. Schwalie, P.C.; Dong, H.; Zachara, M.; Russeil, J.; Alpern, D.; Akchiche, N.; Caprara, C.; Sun, W.; Schlaudraff, K.-U.; Soldati, G.; et al. A stromal cell population that inhibits adipogenesis in mammalian fat depots. Nature 2018, 559, 103-108. [CrossRef]

6. Tyurin-Kuzmin, P.A.; Fadeeva, J.I.; Kanareikina, M.A.; Kalinina, N.I.; Sysoeva, V.Y.; Dyikanov, D.T.; Stambolsky, D.V.; Tkachuk, V.A. Activation of $\beta$-adrenergic receptors is required for elevated $\alpha 1 \mathrm{~A}$-adrenoreceptors expression and signaling in mesenchymal stromal cells. Sci. Rep. 2016, 6, 32835. [CrossRef]

7. Sysoeva, V.Y.; Ageeva, L.V.; Tyurin-Kuzmin, P.A.; Sharonov, G.V.; Dyikanov, D.T.; Kalinina, N.I.; Tkachuk, V.A. Local angiotensin II promotes adipogenic differentiation of human adipose tissue mesenchymal stem cells through type 2 angiotensin receptor. Stem Cell Res. 2017, 25, 115-122. [CrossRef]

8. Lee, H.Y.; Hong, I.S. Double-edged sword of mesenchymal stem cells: Cancer-promoting versus therapeutic potential. Cancer Sci. 2017, 108, 1939-1946. [CrossRef]

9. Liu, S.; Zhou, J.; Zhang, X.; Liu, Y.; Chen, J.; Hu, B.; Song, J.; Zhang, Y. Strategies to optimize adult stem cell therapy for tissue regeneration. Int. J. Mol. Sci. 2016, 17, 982. [CrossRef]

10. Tano, N.; Kaneko, M.; Ichihara, Y.; Ikebe, C.; Coppen, S.R.; Shiraishi, M.; Shintani, Y.; Yashiro, K.; Warrens, A.; Suzuki, K. Allogeneic Mesenchymal Stromal Cells Transplanted Onto the Heart Surface Achieve Therapeutic Myocardial Repair Despite Immunologic Responses in Rats. J. Am. Heart Assoc. 2016, 5, 1-13. [CrossRef] [PubMed]

11. Li, X.; He, X.-T.; Yin, Y.; Wu, R.-X.; Tian, B.-M.; Chen, F.-M. Administration of signalling molecules dictates stem cell homing for in situ regeneration. J. Cell. Mol. Med. 2017, 21, 3162-3177. [CrossRef]

12. Baldari, S.; Di Rocco, G.; Piccoli, M.; Pozzobon, M.; Muraca, M.; Toietta, G. Challenges and Strategies for Improving the Regenerative Effects of Mesenchymal Stromal Cell-Based Therapies. Int. J. Mol. Sci. 2017, 18, 2087. [CrossRef]

13. Salazar, K.D.; Lankford, S.M.; Brody, A.R. Mesenchymal stem cells produce Wnt isoforms and TGF- $\beta 1$ that mediate proliferation and procollagen expression by lung fibroblasts. Am. J. Physiol. Cell. Mol. Physiol. 2009, 297, L1002-L1011. [CrossRef]

14. Lozito, T.P.; Tuan, R.S. Mesenchymal stem cells inhibit both endogenous and exogenous MMPs via secreted TIMPs. J. Cell. Physiol. 2011, 226, 385-396. [CrossRef] [PubMed]

15. Andreeva, E.R.; Matveeva, D.K. Multipotent Mesenchymal Stromal Cells and Extracellular Matrix: Regulation under Hypoxia. Hum. Physiol. 2018, 44, 696-705. [CrossRef]

16. Bhang, S.H.; Lee, S.; Shin, J.-Y.; Lee, T.-J.; Jang, H.-K.; Kim, B.-S. Efficacious and clinically relevant conditioned medium of human adipose-derived stem cells for therapeutic angiogenesis. Mol. Ther. 2014, 22, 862-872. [CrossRef] [PubMed]

17. Kalinina, N.; Kharlampieva, D.; Loguinova, M.; Butenko, I.; Pobeguts, O.; Efimenko, A.; Ageeva, L.; Sharonov, G.; Ischenko, D.; Alekseev, D.; et al. Characterization of secretomes provides evidence for adipose-derived mesenchymal stromal cells subtypes. Stem Cell Res. Ther. 2015, 6, 221. [CrossRef] [PubMed]

18. Pawitan, J.A. Prospect of stem cell conditioned medium in regenerative medicine. Biomed Res. Int. 2014, 2014, 965849. [CrossRef]

19. Liu, H.; Cheng, Y.; Chen, J.; Chang, F.; Wang, J.; Ding, J.; Chen, X. Component effect of stem cell-loaded thermosensitive polypeptide hydrogels on cartilage repair. Acta Biomater. 2018, 73, 103-111. [CrossRef] 
20. Zhang, Z.-Z.; Wang, S.-J.; Zhang, J.-Y.; Jiang, W.-B.; Huang, A.-B.; Qi, Y.-S.; Ding, J.-X.; Chen, X.-S.; Jiang, D.; Yu, J.-K. 3D-Printed Poly(E-caprolactone) Scaffold Augmented with Mesenchymal Stem Cells for Total Meniscal Substitution: A 12- and 24-Week Animal Study in a Rabbit Model. Am. J. Sports Med. 2017, 45, 1497-1511. [CrossRef]

21. Zhang, Y.; Zhang, J.; Chang, F.; Xu, W.; Ding, J. Repair of full-thickness articular cartilage defect using stem cell-encapsulated thermogel. Mater. Sci. Eng. C 2018, 88, 79-87. [CrossRef]

22. Sagaradze, G.D.; Basalova, N.A.; Kirpatovsky, V.I.; Ohobotov, D.A.; Grigorieva, O.A.; Balabanyan, V.Y.; Kamalov, A.A.; Efimenko, A.Y. Application of rat cryptorchidism model for the evaluation of mesenchymal stromal cell secretome regenerative potential. Biomed. Pharmacother. 2019, 109, 1428-1436. [CrossRef]

23. Kirpatovckii, V.I.; Kamalov, D.M.; Efimenko, A.Y.; Makarevich, P.I.; Sagaradze, G.D.; Makarevich, O.A.; Nimiritskii, P.P.; Osidak, E.O.; Domogatskii, S.P.; Karpov, V.K.; et al. Urinary bladder substitution using combined membrane based on secretions of human mesenchymal stem cells and type I collagen. Urologiia 2016, 6, 34-42.

24. Fukuoka, H.; Suga, H.; Narita, K.; Watanabe, R.; Shintani, S. The latest advance in hair regeneration therapy using proteins secreted by adipose-derived stem cells. Am. J. Cosmet. Surg. 2012, 29, 273-282.

25. Zhou, B.R.; Xu, Y.; Xu, Y.; Guo, S.L.; Wang, Y.; Zhu, F.; Permatasari, F.; Wu, D.; Yin, Z.Q.; Luo, D. The effect of conditioned media of adipose-derived stem cells on wound healing after ablative fractional carbon dioxide laser resurfacing. Biomed Res. Int. 2013, 2013. [CrossRef] [PubMed]

26. Kay, A.G.; Long, G.; Tyler, G.; Stefan, A.; Broadfoot, S.J.; Piccinini, A.M.; Middleton, J.; Kehoe, O. Mesenchymal Stem Cell-Conditioned Medium Reduces Disease Severity and Immune Responses in Inflammatory Arthritis. Sci. Rep. 2017, 7, 1-11. [CrossRef] [PubMed]

27. Dahbour, S.; Jamali, F.; Alhattab, D.; Al-Radaideh, A.; Ababneh, O.; Al-Ryalat, N.; Al-Bdour, M.; Hourani, B.; Msallam, M.; Rasheed, M.; et al. Mesenchymal stem cells and conditioned media in the treatment of multiple sclerosis patients: Clinical, ophthalmological and radiological assessments of safety and efficacy. CNS Neurosci. Ther. 2017, 23, 866-874. [CrossRef]

28. Fujita, Y.; Kadota, T.; Araya, J.; Ochiya, T.; Kuwano, K. Clinical Application of Mesenchymal Stem Cell-Derived Extracellular Vesicle-Based Therapeutics for Inflammatory Lung Diseases. J. Clin. Med. 2018, 7, 355. [CrossRef]

29. Gimona, M.; Pachler, K.; Laner-Plamberger, S.; Schallmoser, K.; Rohde, E. Manufacturing of human extracellular vesicle-based therapeutics for clinical use. Int. J. Mol. Sci. 2017, 18, 1190. [CrossRef]

30. Qiu, G.; Zheng, G.; Ge, M.; Wang, J.; Huang, R.; Shu, Q.; Xu, J. Mesenchymal stem cell-derived extracellular vesicles affect disease outcomes via transfer of microRNAs. Stem Cell Res. Ther. 2018, 9, 320. [CrossRef] [PubMed]

31. Fang, S.; Xu, C.; Zhang, Y.; Xue, C.; Yang, C.; Bi, H.; Qian, X.; Wu, M.; Ji, K.; Zhao, Y.; et al. Umbilical Cord-Derived Mesenchymal Stem Cell-Derived Exosomal MicroRNAs Suppress Myofibroblast Differentiation by Inhibiting the Transforming Growth Factor-/SMAD2 Pathway During Wound Healing. Stem Cells Transl. Med. 2016, 5, 1425-1439. [CrossRef] [PubMed]

32. Phinney, D.G.; Pittenger, M.F. Concise Review: MSC-Derived Exosomes for Cell-Free Therapy. Stem Cells 2017, 35, 851-858. [CrossRef] [PubMed]

33. Gunawardena, T.N.A.; Mohammad, T.R.; Abdullah, B.J.J.; Abu Kasim, N.H. Conditioned media serived from mesenchymal stem cell cultures: The next generation for regenerative medicine. J. Tissue Eng. Regen. Med. 2019. [CrossRef] [PubMed]

34. Sagaradze, G.D.; Nimiritsky, P.P.; Akopyan, Z.A.; Makarevich, P.I.; Efimenko, A.Y. “Cell-Free Therapeutics” from Components Secreted by Mesenchymal Stromal Cells as a Novel Class of Biopharmaceuticals. In Biopharmaceuticals; InTech: London, UK, 2018; Volume 2, p. 64. ISBN 9789537619992.

35. Leuning, D.G.; Beijer, N.R.M.; du Fossé, N.A.; Vermeulen, S.; Lievers, E.; van Kooten, C.; Rabelink, T.J.; de Boer, J. The cytokine secretion profile of mesenchymal stromal cells is determined by surface structure of the microenvironment. Sci. Rep. 2018, 8, 7716. [CrossRef] [PubMed]

36. Bravery, C.A.; Carmen, J.; Fong, T.; Oprea, W.; Hoogendoorn, K.H.; Woda, J.; Burger, S.R.; Rowley, J.A.; Bonyhadi, M.L.; Van't Hof, W. Potency assay development for cellular therapy products: An ISCT $*$ review of the requirements and experiences in the industry. Cytotherapy 2013, 15, 9-19.e9. [CrossRef]

37. Mendicino, M.; Bailey, A.M.; Wonnacott, K.; Puri, R.K.; Bauer, S.R. MSC-based product characterization for clinical trials: An FDA perspective. Cell Stem Cell 2014, 14, 141-145. [CrossRef] 
38. Jin, H.; Bae, Y.; Kim, M.; Kwon, S.-J.; Jeon, H.; Choi, S.; Kim, S.; Yang, Y.; Oh, W.; Chang, J. Comparative Analysis of Human Mesenchymal Stem Cells from Bone Marrow, Adipose Tissue, and Umbilical Cord Blood as Sources of Cell Therapy. Int. J. Mol. Sci. 2013, 14, 17986-18001. [CrossRef] [PubMed]

39. Dominici, M.; Le Blanc, K.; Mueller, I.; Slaper-Cortenbach, I.; Marini, F.; Krause, D.; Deans, R.; Keating, A.; Prockop, D.; Horwitz, E. Minimal criteria for defining multipotent mesenchymal stromal cells. The International Society for Cellular Therapy position statement. Cytotherapy 2006, 8, 315-317. [CrossRef] [PubMed]

40. Dzobo, K.; Turnley, T.; Wishart, A.; Rowe, A.; Kallmeyer, K.; van Vollenstee, F.; Thomford, N.; Dandara, C.; Chopera, D.; Pepper, M.; et al. Fibroblast-Derived Extracellular Matrix Induces Chondrogenic Differentiation in Human Adipose-Derived Mesenchymal Stromal/Stem Cells in Vitro. Int. J. Mol. Sci. 2016, 17, 1259. [CrossRef] [PubMed]

41. Odabas, S.; Elçin, A.E.; Elçin, Y.M. Isolation and Characterization of Mesenchymal Stem Cells. Methods Mol. Biol. 2014, 1109, 47-63. [CrossRef]

42. Efimenko, A.; Dzhoyashvili, N.; Starostina, E.; Kalinina, N.; Parfyonova, E. Angiogenic properties of human adipose-derived mesenchymal stem cells decline with donor age owing to the impairment of proangiogenic factors secretion. Regen. Med. 2011, 6, 322-323.

43. Efimenko, A.Y.; Dzhoyashvili, N.; Kalinina, N.; Kochegura, T.; Akchurin, R.; Tkachuk, V.; Parfyonova, Y. Adipose-derived mesenchymal stromal cells from aged patients with coronary artery disease keep mesenchymal stromal cell properties but exhibit characteristics of aging and have impaired angiogenic potential. Stem Cells Transl. Med. 2014, 3, 32-41. [CrossRef]

44. Method for Stimulating Regenerative Processes in Ischemic Tissues. Available online: https://patents. google.com/patent/RU2497529C2/en (accessed on 25 February 2019).

45. Kim, H.-K.; Lee, S.-G.; Lee, S.-W.; Oh, B.J.; Kim, J.H.; Kim, J.A.; Lee, G.; Jang, J.-D.; Joe, Y.A. A Subset of Paracrine Factors as Efficient Biomarkers for Predicting Vascular Regenerative Efficacy of Mesenchymal Stromal/Stem Cells. Stem Cells 2019, 37, 77-88. [CrossRef] [PubMed]

46. Ling, L.; Feng, X.; Wei, T.; Wang, Y.; Wang, Y.; Wang, Z.; Tang, D.; Luo, Y.; Xiong, Z. Human amnion-derived mesenchymal stem cell (hAD-MSC) transplantation improves ovarian function in rats with premature ovarian insufficiency (POI) at least partly through a paracrine mechanism. Stem Cell Res. Ther. 2019, 10, 46. [CrossRef] [PubMed]

47. Shi, Y.; Hu, G.; Su, J.; Li, W.; Chen, Q.; Shou, P.; Xu, C.; Chen, X.; Huang, Y.; Zhu, Z.; et al. Mesenchymal stem cells: A new strategy for immunosuppression and tissue repair. Cell Res. 2010, 20, 510-518. [CrossRef]

48. Hass, R.; Kasper, C.; Böhm, S.; Jacobs, R. Different populations and sources of human mesenchymal stem cells (MSC): A comparison of adult and neonatal tissue-derived MSC. Cell Commun. Signal. 2011, 9, 12. [CrossRef]

49. Valtieri, M.; Sorrentino, A. The mesenchymal stromal cell contribution to homeostasis. J. Cell. Physiol. 2008, 217, 296-300. [CrossRef]

50. Gnecchi, M.; Danieli, P.; Malpasso, G.; Ciuffreda, M.C. Paracrine Mechanisms of Mesenchymal Stem Cells in Tissue Repair. Methods Mol. Biol. 2016, 1416, 123-146.

51. Nimiritsky, P.; Eremichev, R.; Alexandrushkina, N.; Efimenko, A.; Tkachuk, V.; Makarevich, P. Unveiling Mesenchymal Stromal Cells' Organizing Function in Regeneration. Int. J. Mol. Sci. 2019, 20, 823. [CrossRef]

52. Kichenbrand, C.; Velot, E.; Menu, P.; Moby, V. Dental Pulp Stem Cell-Derived Conditioned Medium: An Attractive Alternative for Regenerative Therapy. Tissue Eng. Part B Rev. 2018, 1-35. [CrossRef] [PubMed]

53. Ikebe, C.; Suzuki, K. Mesenchymal stem cells for regenerative therapy: optimization of cell preparation protocols. Biomed Res. Int. 2014, 2014, 951512. [CrossRef] [PubMed]

54. Oikonomopoulos, A.; Deen, W.K. Van; Manansala, A.; Lacey, P.N.; Tomakili, T.A.; Ziman, A.; Hommes, D.W. Optimization of human mesenchymal stem cell manufacturing: The effects of animal/xeno-free media. Nat. Publ. Gr. 2015, 1-11. [CrossRef] [PubMed]

55. Madrigal, M.; Rao, K.S.; Riordan, N.H. A review of therapeutic effects of mesenchymal stem cell secretions and induction of secretory modification by different culture methods. J. Transl. Med. 2014, 12, 260. [CrossRef] [PubMed] 
56. Belinsky, G.S.; Sreekumar, B.; Andrejecsk, J.W.; Saltzman, W.M.; Gong, J.; Herzog, R.I.; Lin, S.; Horsley, V.; Carpenter, T.O.; Chung, C. Pigment epithelium-derived factor restoration increases bone mass and improves bone plasticity in a model of osteogenesis imperfecta type VI via Wnt3a blockade. FASEB J. 2016, 30, 2837-2848. [CrossRef]

57. Fan, W.; Crawford, R.; Xiao, Y. The ratio of VEGF/PEDF expression in bone marrow mesenchymal stem cells regulates neovascularization. Differentiation. 2011, 81, 181-191. [CrossRef] [PubMed]

58. Zhang, Y.; Li, R.; Rong, W.; Han, M.; Cui, C.; Feng, Z.; Sun, X.; Jin, S. Therapeutic effect of hepatocyte growth factor-overexpressing bone marrow-derived mesenchymal stem cells on CCl4-induced hepatocirrhosis. Cell Death Dis. 2018, 9, 1186. [CrossRef] [PubMed]

59. Song, Y.H.; Zhu, Y.T.; Ding, J.; Zhou, F.Y.; Xue, J.X.; Jung, J.H.; Li, Z.J.; Gao, W.Y. Distribution of fibroblast growth factors and their roles in skin fibroblast cell migration. Mol. Med. Rep. 2016, 14, 3336-3342. [CrossRef] [PubMed]

60. Cartland, S.P.; Genner, S.W.; Zahoor, A.; Kavurma, M.M. Comparative evaluation of trail, FGF-2 and VEGF-A-Induced angiogenesis in vitro and in vivo. Int. J. Mol. Sci. 2016, 17, 2025. [CrossRef]

61. Lai, R.C.; Arslan, F.; Lee, M.M.; Sze, N.S.K.; Choo, A.; Chen, T.S.; Salto-Tellez, M.; Timmers, L.; Lee, C.N.; El Oakley, R.M.; et al. Exosome secreted by MSC reduces myocardial ischemia/reperfusion injury. Stem Cell Res. 2010, 4, 214-222. [CrossRef]

62. Lee, M.S.; Youn, C.; Kim, J.H.; Park, B.J.; Ahn, J.; Hong, S.; Kim, Y.D.; Shin, Y.K.; Park, S.G. Enhanced cell growth of adipocyte-derived mesenchymal stem cells using chemically-defined serum-free media. Int. J. Mol. Sci. 2017, 18, 1779. [CrossRef]

63. Zhang, Q.; Sun, X.; Ding, J.; He, P.; Liu, Y.; Cheng, H.; Zhou, C.; Meng, X. Autoserum: An Optimal Supplement for Bone Marrow Mesenchymal Stem Cells of Liver-Injured Rats. Stem Cells Int. 2015, 2015, 1-10. [CrossRef]

(C) 2019 by the authors. Licensee MDPI, Basel, Switzerland. This article is an open access article distributed under the terms and conditions of the Creative Commons Attribution (CC BY) license (http:/ / creativecommons.org/licenses/by/4.0/). 